\title{
The Association between Female Genital Cutting and Spousal HCV Infection in Egypt
}

\author{
Chris R. Kenyon ${ }^{1}$ and Robert Colebunders ${ }^{2}$ \\ ${ }^{1}$ Sexually Transmitted Infections, HIV/STI Unit, Institute of Tropical Medicine, Nationalestraat 155, 2000 Antwerpen, Belgium \\ ${ }^{2}$ Infectious Diseases, University of Antwerp (UA), HIV/STD Unit, Institute of Tropical Medicine, Nationalestraat 155, \\ 2000 Antwerpen, Belgium
}

Correspondence should be addressed to Chris R. Kenyon; ckenyon@itg.be

Received 30 December 2013; Revised 19 February 2014; Accepted 20 February 2014; Published 20 March 2014

Academic Editor: Matthias Bahr

Copyright (C) 2014 C. R. Kenyon and R. Colebunders. This is an open access article distributed under the Creative Commons Attribution License, which permits unrestricted use, distribution, and reproduction in any medium, provided the original work is properly cited.

Objective. To identify the risk factors for HCV infection within married couples in Egypt. Methods. In 2008 Egypt conducted its first nationally representative survey of HCV prevalence. 11126 of the 12780 individuals aged 15-59 year who were sampled agreed to participate and provided information via a questionnaire about demographic and behavioural characteristics and blood for HCV antibody and RNA analysis. We assessed the risk factors for HCV infection in a subsample of 5182 married individuals via multivariate logistic regression. Results. Overall HCV antibody prevalence in the married couples was 18.2\% (95\% CI, 16.8-19.6). HCV antibody prevalence was higher in the husbands (23.7\%) than the wives $(12.1 \% ; P<0.001)$. Having a spouse who was infected with HCV was an independent risk factor for HCV infection with odds ratios of 2.1 (95\% CI, 1.6-2.9) and 2.2 (95\% CI, 1.6-3.1) for women and men, respectively. Husbands whose wives had experienced female genital cutting (FGC) had a higher prevalence of HCV and this relationship was driven by a strong association in urban areas. Amongst the women there was no association between FGC and HCV overall but in urban areas only women who had experienced FGC were HCV infected. Conclusions. This study provides additional evidence of the importance of intrafamilial transmission of HCV in Egypt.

\section{Introduction}

With $14.7 \%$ of $15-59$-year-olds testing anti-HCV positive, Egypt has the highest HCV prevalence in the world [1]. Although parenteral antischistosomiasis therapy (PAT) was important in the genesis of Egypt's HCV epidemic this was stopped over 25 years ago and HCV incidence remains high estimated between 150000 and 500000 new infections per year [2-4]. Infection from inadequate sterility of dental and medical devices has been shown to play a role in this regard $[1,2,5-12]$. Intrafamilial transmission is an alternative explanation [6]. Support for this theory comes from studies such as a longitudinal study of incidence in two villages in Egypt, which found that the strongest predictor of incident of HCV was having an anti-HCV positive family member [13]. Among those that did and did not have a family member infected with HCV, HCV incidence was 5.8 and 1.0/1000 person years, respectively. Parenteral exposure increased the risk of HCV but was not statistically significant.
This elevated risk of incident of HCV of family members could be due to sharing of implements such as razors or toothbrushes or due to sexual transmission between family members $[14,15]$. Alternatively, the elevated risk may be due to shared risk factors (such as the family members all attending a particular health practitioner) rather than being caused by direct transmission between family members [13].

To disentangle these relationships it would be useful to know how HCV is patterned within families. If a husband, is infected is this associated with an increased risk of his wife being infected and vice versa? Is the risk higher for a spouse than nonspousal family members? Are these relationships affected by whether the affected individuals are HCV RNA as opposed to antibody positive?

In 2008 Egypt conducted its first nationally representative survey of HCV prevalence-the 2008 Egyptian Demographic and Health Survey (EDHS). A recently published analysis of this survey found that HCV prevalence increased steadily with age but more so in men than women, reaching, in the 


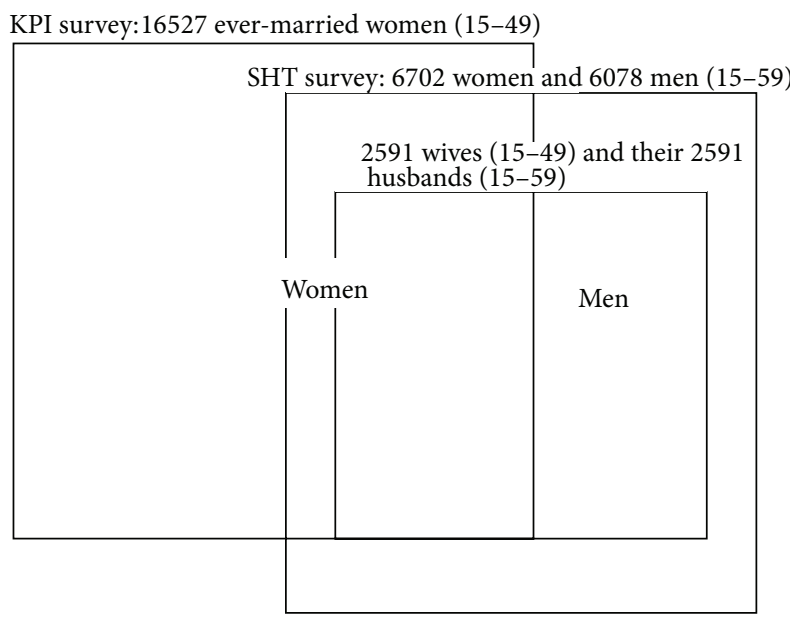

FIGURE 1: The structure of the Egyptian DHS 2008 and the derivation of the married couples subsample. 16527 ever-married women aged 15-49 were sampled in the key population indicators (KPI) survey. In a subsample of households surveyed in the KPI, 6702 women and 6078 men aged 15-49 were sampled in the special health topics (SHT) component. 2591 wives (aged 15-49) and their 2591 husbands (aged 15-59) could be linked to generate the married couples subsample.

50-59-year-age group, $46.3 \%$ in men and $30.8 \%$ in women [1]. HCV was also more prevalent in rural than urban areas and on multivariate analysis it was found to be associated with male sex, age, poverty, past history of PAT, and blood transfusion. In urban regions, those with a lack of education and females with genital cutting were more likely to be HCV infected.

This analysis did not however examine the extent to which $\mathrm{HCV}$ infection covaried within couples and families. The EDHS is the first HCV survey in the world that is both nationally representative and done in a way which enables researchers to link the HCV status of husbands and wives. In this paper we assess the correlates of HCV infection in 2591 married couples from the EDHS.

\section{Materials and Methods}

The EDHS entailed a three-stage probability sample that provided a nationally representative sample of 16527 evermarried women aged 15-49 who were interviewed about a range of key population indicators (KPI). In addition, in a subsample of 4953 households, 6702 women and 6078 men aged 15-59 were sampled for a special health topics (SHT) component (see Figure 1). The overall response rate for this latter section was $96.2 \%$ and $87.6 \%$ for the men and women, respectively. $11126(87.1 \%)$ of these agreed to provide blood for HCV testing. This SHT component was selected so as to provide a sample which was representative for Egypt and the six major areas that the EDHS was stratified by: Urban and Frontier governorates and Upper and Lower Egypt (each of the latter two was divided into rural and urban areas). In order to link husbands and wives, we made use of the fact that 3877 women completed both questionnaires. These were the women who had ever been married, were 14-49 years old, and completed the KPI questionnaire. If the respondent was currently married, then the KPI questionnaire specified the husband's line number within their house. This provides a unique identifier for each husband. Via this mechanism, we established that, in the case of 2591 individuals, the husband of a respondent also completed the SHT component of the EDHS. In this paper we study the relationships between $\mathrm{HCV}$ and various risk factors in these 2591 husband-wife pairs. Apart from the 5182 individuals in this married subgroup, further 2338 persons aged 15-59 years, living in the same houses as the married couples, were included in the SHT survey. Although the outcome variable used in this study is the presence of anti-HCV antibodies in the 5182 members of the married subgroup, the relationship between the HCV serostatus of the married couples and that of the other household members is also of relevance. We therefore included the HCV antibody and RNA status of these 2338 individuals as exposure variables in our analyses. We also calculated the HCV prevalence for each of Egypt's 26 governorates. These were used as a measure of local or community HCV prevalence.

Unless otherwise stated the terms "HCV prevalence" and "infection" refer to $\mathrm{HCV}$ antibody prevalence. The $\mathrm{HCV}$ antibody prevalence rates were calculated for a range of potential risk factors available in the special health topics questionnaire. Because of the strong association between age and $\mathrm{HCV}$ prevalence all the odds ratios and $P$ values given are age-adjusted. Logistic regression was used to explore the strength of the association of each variable with $\mathrm{HCV}$ infection in the 5192 individuals in the married couples cohort.

Tests for interaction between variables were conducted. These tests revealed that the effect of several of the variables varied according to urban/rural location and men/women. As a result, separate models were constructed for men and women as well as urban and rural areas. All the urban women who had not undergone female genital cutting were HCV negative. To avoid the collinearity that this created in the analyses, for the analysis limited to urban women, we randomly selected one urban woman who had not undergone female genital cutting and changed her $\mathrm{HCV}$ status as positive. The final models were constructed by including all variables with $P$ values $<0.2$ on univariate logistic regression. The education variable was not included due to significant collinearity with the income variable. The HCV status of the spouse and that of the other household members (both exposure variables) were represented by HCV RNA instead of HCV antibody positivity in the multivariate models due to exerting a stronger effect on the outcome variable (and considerable collinearity between the RNA and antibody HCV tests). All analyses were weighted to account for the sampling and survey design. Statistical analysis was conducted using STATA version 12.0 (StataCorp, College Station, TX).

The HCV prevalence rates for the husbands and wives were also stratified by the wives' excision status to explore how HCV prevalence in both husbands and wives varies according to the excision status of the woman. The terms excision and female genital cutting (FGC) are used synonymously 
in the paper. The FGC variable was defined as follows: both the women who had experienced FGC and the men whose wives had undergone FGC were coded as 1 and the women and men whose wives had not undergone FGC were coded as 0 . To assess the impact of whether HCV prevalence in women was associated with who conducted the FGC, a second FGC variable, termed FGC-operator, was constructed as follows: women with no history of FGC coded 0, FGC performed by doctor and nondoctor coded as 1 and 2, respectively. The multivariate models for women were run separately with the FGC and FGC-operator variables.

A third generation enzyme-linked immunosorbent assay was used to detect HCV antibodies (Adaltis EIAgen HCV $\mathrm{Ab}$, Casalecchio di Reno, Italy). Positive tests were confirmed by a chemiluminescent microplate immunoassay (CIA). Seropositive specimens were tested for HCV RNA using the RealTime_m2000 system (Abbott Laboratories, Abbott Park, IL, USA). Full details of the survey and sampling strategy have been previously published $[1,16]$.

\section{Results}

Overall HCV antibody prevalence in the married couples was $18.2 \%$ (95\% CI, 16.8-19.6). HCV antibody prevalence was higher in the husbands $(23.7 \%)$ than the wives $(12.1 \%$; $P<0.001$; see Table 1). Restricting this analysis to the $15-$ 49-year-olds reduced the difference in HCV between the husbands and wives (18.8\% and $11.6 \%$ resp. $P<0.001)$. $\mathrm{HCV}$ prevalence was also higher in rural (20.4\%) than urban (12.0\%) regions $(P<0.001)$. HCV prevalence increased steadily with age reaching $30.2 \%$ (95\% CI, 26.8-33.8) in men and $23.9 \%$ (95\% CI, 20.4-27.7) in women in the 41-49-yearold category. Amongst women, there was a stepwise increase in HCV prevalence with increasing number of children: $6.9 \%$ if $0-2$ children, $14.1 \%$ if $3-5$ children, and $24.5 \%$ if more than 5 children. There was a lower HCV prevalence in those who had completed secondary level education (14.3\%) compared to those with no education $(23.5 \%$; $P=0.001)$ and those in the top two income quintiles (12.1 and 12.9\%) compared to those in the poorest quintile $(22.8 \% ; P<0.001)$. HCV prevalence in persons who had received PAT (32.1\%) was higher than in those who had not (16.5\%; $P<0.001)$. Women with excision had a trend to higher HCV prevalence $(12.5 \%)$ than those without $(3.9 \% ; P=0.096$; see Tables 1 and 2). Men whose wives had been excised had a higher HCV prevalence than those whose wives had not $(23.7 \%$ versus $8.3 \%$; $P=0.003$ ). Women who had been excised by a doctor had a lower HCV prevalence than those excised by a nondoctor ( $5.6 \%$ versus $13.7 \% ; P=0.003$ ). Respondents who had received a blood transfusion had nonsignificantly higher HCV prevalence rates than those who had not (26.9\% versus $17.8 \% ; P=0.132)$. HCV prevalence increased with length of marriage, increasing from $8.2 \%$ to 17.6 and $29.6 \%$ in those married for ten years or less, 11-20 years, and over 20 years, respectively. Having received injections and dental treatment were not associated with HCV seropositivity.

Persons with an HCV seropositive partner had a higher HCV prevalence than those who did not (32.6\% versus $15.1 \%$; $P<0.001)$. This effect was also evident if one's partner was
RNA positive for $\mathrm{HCV}$ (34.7\% versus $15.9 \% ; P<0.001)$. The effect was not as marked if it was another member of the household who was HCV antibody (23.3\% versus $17.7 \%$; $P=0.004)$ or RNA positive (23\% versus $17.9 \%$; $P=0.015$ ).

In the multivariate logistic regression analyses, three variables were associated with HCV infection in all models; see Table 3. These were age, local HCV prevalence, and having a spouse who was infected with HCV. Having a nonspousal household member who was HCV infected was not independently associated with HCV. For both men and women HCV was less prevalent in the richer quintiles but in the case of men this effect was evident in the urban but not the rural areas.

$\mathrm{HCV}$ was associated with a blood transfusion in women but this association only applied to the rural areas. PAT was associated with HCV in all the models except in the men in the rural and the women in the urban areas. Being married for longer than 20 years was associated with $\mathrm{HCV}$, but only for men. FGC was associated with $\mathrm{HCV}$ infection in the men but not the women overall. This relationship in men was driven by a relatively strong association in urban areas. Amongst the women, there was no association between FGC and $\mathrm{HCV}$ overall but in urban areas none of the women who were not excised were $\mathrm{HCV}$ infected. In the second set of women's models substitution of the FGC variable with the FGC-operator variable had little effect. FGC had no effect in rural areas and a strong effect in urban areas regardless of whether it was conducted by a doctor or nondoctor (data not shown).

The EDHS reveals that, of the women who had undergone FGC, $99.9 \%$ had done so by the age of 18 . Of the women aged 15-18 surveyed in the EDHS, the HCV prevalence was significantly higher in those who had been excised (39/723; $5.4 \%)$ than those who had not $(0 / 164 ; 0 \%, P=0.028)$.

There was no evidence of interaction between the wife's FGC status and HCV status of the partner variables.

\section{Discussion}

Linking husbands and wives allowed us to test the association of HCV infection between husbands and wives. This represents the first time that this has been done in a nationally representative HCV survey. The sampling strategy used to describe the epidemiology of HCV in the USA, although nationally representative, does not include sexual partners in a linked way that would allow a similar analysis [17]. We found an association between the HCV status of the respondent and their partner. This is true for analyses limited to rural and urban areas and for subanalyses of men and women within these areas. The association remains after controlling for other members of the household being HCV infected. The relationship is slightly stronger when the HCV in the partner is measured with an RNA-based as opposed to an antibody-based test.

If not due to confounding, this association may be due to nonsexual intrafamilial transmission (such as shared utensils, toothbrushes, and razors), sexual transmission, or shared risk exposures (such as attending to the same health care practitioner). If the former was predominant then we should 
TABLE 1: HCV seroprevalence and age-adjusted odds ratios for selected characteristics (Egyptian DHS 2008).

\begin{tabular}{|c|c|c|c|c|}
\hline Risk factors & $\begin{array}{c}\text { Number of } \\
\text { exposed }(\%)^{\mathrm{a}}\end{array}$ & $\begin{array}{c}\text { Number of HCV } \\
\text { antibody positive } \\
(\%)^{b}\end{array}$ & $\begin{array}{l}\text { Age-adjusted OR } \\
(95 \% \mathrm{CI})\end{array}$ & $\begin{array}{c}P \text { value } \\
\text { (age-adjusted) }\end{array}$ \\
\hline \multicolumn{5}{|l|}{ Place of residence } \\
\hline Rural & $3234(37.6)$ & $661(20.4)$ & $2.4(1.9-3.0)$ & $<0.001$ \\
\hline Urban & $1948(62.4)$ & $233(12.0)$ & 1 & \\
\hline \multicolumn{5}{|l|}{ Region } \\
\hline Urban governorates & $610(11.8)$ & $76(12.6)$ & 1 & \\
\hline Lower Egypt-urban & $554(10.7)$ & $69(12.3)$ & $1.0(0.7-1.5)$ & 0.994 \\
\hline Lower Egypt-rural & $1608(31.0)$ & $364(22.9)$ & $2.7(1.9-3.8)$ & $<0.001$ \\
\hline Upper Egypt—urban & $600(11.6)$ & $79(13.5)$ & $1.1(0.7-1.7)$ & 0.778 \\
\hline Upper Egypt—rural & $1524(29.4)$ & $294(20.1)$ & $2.1(1.5-3.0)$ & $<0.001$ \\
\hline Frontier governorates & $286(5.5)$ & $12(4.5)$ & $0.3(0.2-0.6)$ & 0.001 \\
\hline \multicolumn{5}{|l|}{ Gender } \\
\hline Women & $2591(50)$ & $300(12.1)$ & $0.7(0.6-0.9)$ & $<0.001$ \\
\hline Men & $2591(50)$ & $594(23.7)$ & 1 & \\
\hline \multicolumn{5}{|l|}{ Men's age (years) } \\
\hline $15-20$ & $9(0.4)$ & $0(0)$ & & \\
\hline $21-30$ & $524(20.2)$ & $50(9.5)$ & 1 & \\
\hline $31-40$ & $877(33.9)$ & $117(13.3)$ & $1.5(1.0-2.1)$ & 0.034 \\
\hline $41-49$ & $827(31.9)$ & $268(32.4)$ & $4.5(3.3-6.3)$ & 0.000 \\
\hline $50-59$ & $354(13.7)$ & $159(44.9)$ & $7.7(5.4-11.1)$ & 0.000 \\
\hline \multicolumn{5}{|l|}{ Women's age (years) } \\
\hline $15-20$ & $154(5.9)$ & $5(3.3)$ & 1 & \\
\hline $21-30$ & $1018(39.3)$ & $60(5.9)$ & $1.8(0.7-4.7)$ & 0.188 \\
\hline $31-40$ & $860(33.2)$ & $104(12.1)$ & $4.1(1.6-10.2)$ & 0.002 \\
\hline $41-49$ & $559(21.6)$ & $131(23.4)$ & $9.1(3.6-22.7)$ & 0.000 \\
\hline \multicolumn{5}{|l|}{ Educational attainment } \\
\hline Secondary completed & $2424(46.8)$ & $282(14.3)$ & $0.7(0.6-0.9)$ & 0.001 \\
\hline Incomplete secondary or less & $1473(28.4)$ & $282(19.9)$ & $0.9(0.7-1.1)$ & 0.219 \\
\hline No education & $1285(24.8)$ & $330(23.5)$ & 1 & \\
\hline \multicolumn{5}{|l|}{ Wealth index quintile } \\
\hline Richest & $1010(19.5)$ & $118(12.1)$ & $0.4(0.3-0.5)$ & $<0.001$ \\
\hline Rich & $942(18.2)$ & $112(12.9)$ & $0.5(0.4-0.7)$ & $<0.001$ \\
\hline Middle & $1128(21.7)$ & $225(21.2)$ & $0.9(0.7-1.2)$ & 0.413 \\
\hline Poor & $1056(20.4)$ & $220(22.0)$ & $0.9(0.7-1.2)$ & 0.600 \\
\hline Poorest & $1046(20.2)$ & $219(22.8)$ & 1 & \\
\hline \multicolumn{5}{|c|}{ Parenteral antischistosomiasis therapy } \\
\hline No & $4582(88.4)$ & $707(16.5)$ & 1 & \\
\hline Yes & $600(11.6)$ & $187(32.1)$ & $1.7(1.4-2.2)$ & $<0.001$ \\
\hline \multicolumn{5}{|l|}{ Women: reports FGC ${ }^{c}$} \\
\hline No & $132(5.1)$ & $4(3.9)$ & 1 & \\
\hline Yes & $2459(94.9)$ & $296(12.5)$ & $2.9(0.8-10.1)$ & 0.096 \\
\hline \multicolumn{5}{|l|}{ Men: his wife reports FGC ${ }^{d}$} \\
\hline No & $132(5.1)$ & $11(8.3)$ & 1 & \\
\hline Yes & $2459(94.9)$ & $583(23.7)$ & $3.1(1.5-6.6)$ & 0.003 \\
\hline \multicolumn{5}{|l|}{ FGC performed by ${ }^{\mathrm{g}}$} \\
\hline Doctor & $386(15.7)$ & $21(5.6)$ & 1 & \\
\hline
\end{tabular}


TABLE 1: Continued.

\begin{tabular}{|c|c|c|c|c|}
\hline Risk factors & $\begin{array}{c}\text { Number of } \\
\text { exposed }(\%)^{\mathrm{a}}\end{array}$ & $\begin{array}{l}\text { Number of HCV } \\
\text { antibody positive } \\
(\%)^{\mathrm{b}}\end{array}$ & $\begin{array}{l}\text { Age-adjusted OR } \\
(95 \% \mathrm{CI})\end{array}$ & $\begin{array}{c}P \text { value } \\
\text { (age-adjusted) }\end{array}$ \\
\hline Nondoctor & $2073(84.3)$ & $275(13.7)$ & $1.4(1.1-1.7)$ & 0.003 \\
\hline \multicolumn{5}{|c|}{ Blood transfusion } \\
\hline No & $4931(95.3)$ & $832(17.8)$ & 1 & \\
\hline Yes & $244(4.7)$ & $60(26.9)$ & $1.3(0.9-1.8)$ & 0.132 \\
\hline \multicolumn{5}{|c|}{ Multiple injections ${ }^{\mathrm{e}}$} \\
\hline No & $4301(83.0)$ & $751(18.4)$ & 1 & \\
\hline Yes & $881(17.0)$ & $143(17.1)$ & $0.9(0.7-1.1)$ & 0.312 \\
\hline \multicolumn{5}{|c|}{ Dental treatment $^{\mathrm{e}}$} \\
\hline No & $1829(35.3)$ & $270(15.3)$ & 1 & \\
\hline Yes & $3353(64.7)$ & $624(19.6)$ & $1.1(0.8-1.2)$ & 0.609 \\
\hline \multicolumn{5}{|c|}{ Total number of children ${ }^{\mathrm{h}}$} \\
\hline $0-2$ & $1098(42.4)$ & $73(6.9)$ & 1 & \\
\hline $3-5$ & $1162(44.9)$ & $154(14.1)$ & $1.2(1.0-1.6)$ & 0.427 \\
\hline$\geq 6$ & $331(12.8)$ & $73(24.5)$ & $2.1(1.0-2.5)$ & 0.035 \\
\hline \multicolumn{5}{|c|}{ Partner is seropositive for $\mathrm{HCV}$} \\
\hline No & $4288(82.8)$ & $608(15.1)$ & 1 & \\
\hline Yes & $894(17.3)$ & $286(32.6)$ & $2.1(1.6-2.7)$ & $<0.001$ \\
\hline \multicolumn{5}{|c|}{ Partner is HCV RNA positive } \\
\hline No & $4569(88.2)$ & $686(15.9)$ & 1 & \\
\hline Yes & $613(11.8)$ & $208(34.7)$ & $2.3(1.7-2.9)$ & $<0.001$ \\
\hline \multicolumn{5}{|c|}{ Wife is HCV RNA positive } \\
\hline No & $2291(88.4)$ & $451(20.4)$ & 1 & \\
\hline Yes & $300(11.6)$ & $143(47.4)$ & $2.6(2.0-3.4)$ & $<0.001$ \\
\hline \multicolumn{5}{|c|}{ Husband is HCV RNA positive } \\
\hline No & $1997(77.0)$ & $157(8.3)$ & 1 & \\
\hline Yes & $594(22.9)$ & $143(24.3)$ & $2.5(1.9-3.3)$ & $<0.001$ \\
\hline \multicolumn{5}{|c|}{ Another household member is seropositive for $\mathrm{HCV}$} \\
\hline No & $4760(91.9)$ & $798(17.7)$ & 1 & \\
\hline Yes & $422(8.1)$ & $96(23.3)$ & $1.6(1.2-2.1)$ & 0.004 \\
\hline \multicolumn{5}{|c|}{ Another household member is HCV RNA positive } \\
\hline No & $4896(94.5)$ & $834(17.9)$ & 1 & \\
\hline Yes & $286(5.5)$ & $60(23.0)$ & $1.5(1.1-2.1)$ & 0.015 \\
\hline \multicolumn{5}{|c|}{ Length of marriage } \\
\hline 0-10 years & $2430(46.9)$ & $258(8.2)$ & 1 & \\
\hline $11-20$ years & $1574(30.4)$ & 339 (17.6) & $1.2(1.0-1.5)$ & 0.051 \\
\hline$>20$ years & $1178(22.7)$ & $461(29.8)$ & $1.4(1.1-1.8)$ & 0.016 \\
\hline
\end{tabular}

FGC: female genital cutting.

${ }^{\mathrm{a}}$ Unweighted percentage.

${ }^{\mathrm{b}}$ Weighted percentage.

${ }^{c}$ Numbers for this row are for women only.

${ }^{\mathrm{d}}$ Numbers for this row are for men only.

${ }^{\mathrm{e}}$ Defined as 2 or more injections reported in the preceding 6 months.

${ }^{\mathrm{f}}$ Ever received dental treatment of any sort.

${ }^{\mathrm{g}}$ Of all women who report undergoing FGC

${ }^{\mathrm{h}}$ The total number of children that women report giving birth to. 
TABLE 2: Prevalence of HCV antibodies in 2591 husband-wife pairs, stratified by female genital cutting (FGC) status of the woman (Egyptian DHS 2008).

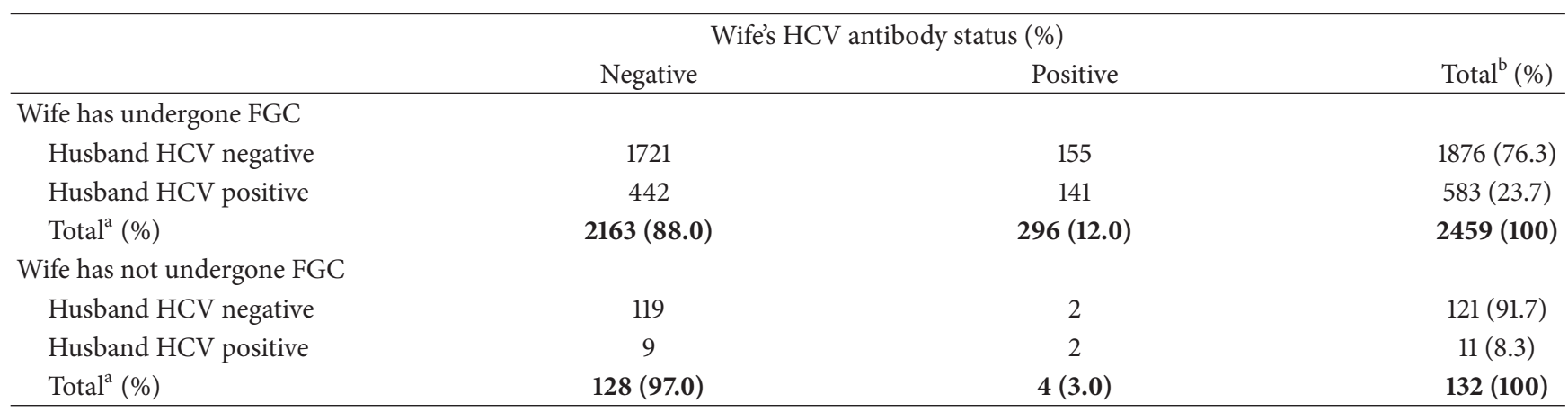

${ }^{\mathrm{a}}$ Row percentages.

${ }^{\mathrm{b}}$ Column percentages.

expect an association between HCV infection in nonspousal family members and in respondents. There was no evidence of such an association in any of the multivariate models. In our models we controlled for a large number of plausible, shared risk exposure types (such as blood transfusions, multiple injections, and PAT), but these did not affect the strength of the relationship between respondent and partner $\mathrm{HCV}$ status. The stronger association between the respondent's $\mathrm{HCV}$ status and that of their wife/husband as opposed to that of other family members may be mediated by the greater length of time they spent together. The fact that there is a relationship between length of marriage and $\mathrm{HCV}$ infection (for men) could be interpreted as supporting evidence for this idea. It does not however explain why this relationship only applies to men. An alternative explanation, and one that is also supported by the relationship between HCV infection and length of marriage, is that sexual transmission between partners is responsible for the relationship of $\mathrm{HCV}$ infection in married couples.

We cannot however exclude the possibility that the reason why the association between the wife and the husband's $\mathrm{HCV}$ status remains strongly positive after controlling for the HCV status of the other household members is due to the partner's HCV status being a better measure of general (nonsexual) infection pressure than the HCV status of the other household members. In the models we do control for the HCV in the surrounding community, but this is defined at the level of the governorate. This may not be a local enough measure of community HCV prevalence.

The relationship between HCV and FGC is complex. There is a strong relationship between HCV infection and FGC in the urban areas but none in the rural areas. There was little sex-based difference. For the men in the urban areas there is an association between HCV infection and having a wife who was excised (OR 3; 95\% CI, 1.1-7.9). In the case of women, none of the nonexcised women had HCV infection.

How do we explain the discrepancy between the rural and urban areas? One possibility is that circumcision in urban areas is more likely to transmit HCV. Though this is possible, it should be noted that it is circumcision by nondoctors that is most strongly correlated with HCV infection [18] and in rural areas the proportion of FGC performed by nondoctors is higher $(84.2 \%)$ than in urban areas $(73.0 \% ; P<0.001)[18]$. Another possibility is that FGC is so prevalent in the rural areas $(97.2 \%)$ that there are too few nonexcised women to be able to demonstrate an effect of FGC on HCV prevalence. For example, in two of the other studies, to consider the impact of FGC on HCV in Egypt, no effect was found, but this may have been due to the extremely low numbers of persons not excised. In the first study there was only one person (out of 1989 individuals in the survey over the age of 20) who was not excised [5]. In the second study, only 4 women out of $1051(0.4 \%)$ over the age of 30 were not excised. This study found a nonsignificant increase in the risk of HCV infection in those women who had been excised by an informal health care provider as opposed to those nonexcised combined with those excised by a formal health care provider (OR 1.6; 95\% CI, 0.7-3.8). In a separate analysis of the EDHS a strong ecological association was found between the prevalence of FGC and HCV at the governorate level [18].

FGC has been associated with range of infections [19]. A population-based, cross-sectional study from the Gambia, for example, found a strong association between prevalent FGC and herpes simplex virus-2 infection (OR 4.7, 95\% CI, 3.7-6.4) and a weaker association between FGC and bacterial vaginosis [20]. A case-control study of primary infertility in Sudan found more extensive forms of FGC to be more prevalent in the cases [21]. There were too few cases and controls without FGC in Sudan study to allow any analysis of those with versus those without FGC. The evidence from Egypt is mixed. A case control study of the determinants of infertility found that cases were more likely to have been excised by a traditional practitioner and more likely to have had more extensive forms of FGC [22]. A later study found no association between FGC and infertility [23].

What could be the possible mechanisms for FGC to result in increased rates of HCV for both men and women? Inadequate sterilization of implements used to perform FGC could be a factor. The higher HCV prevalence in excised versus nonexcised 15-18-year-olds in the EDHS could be interpreted as evidence supporting this nonsterility hypothesis. In addition, HCV transmission at the time of FGC could have been greater in the past when a considerably greater proportion of FGC procedures were performed by nondoctors [18]. Two 


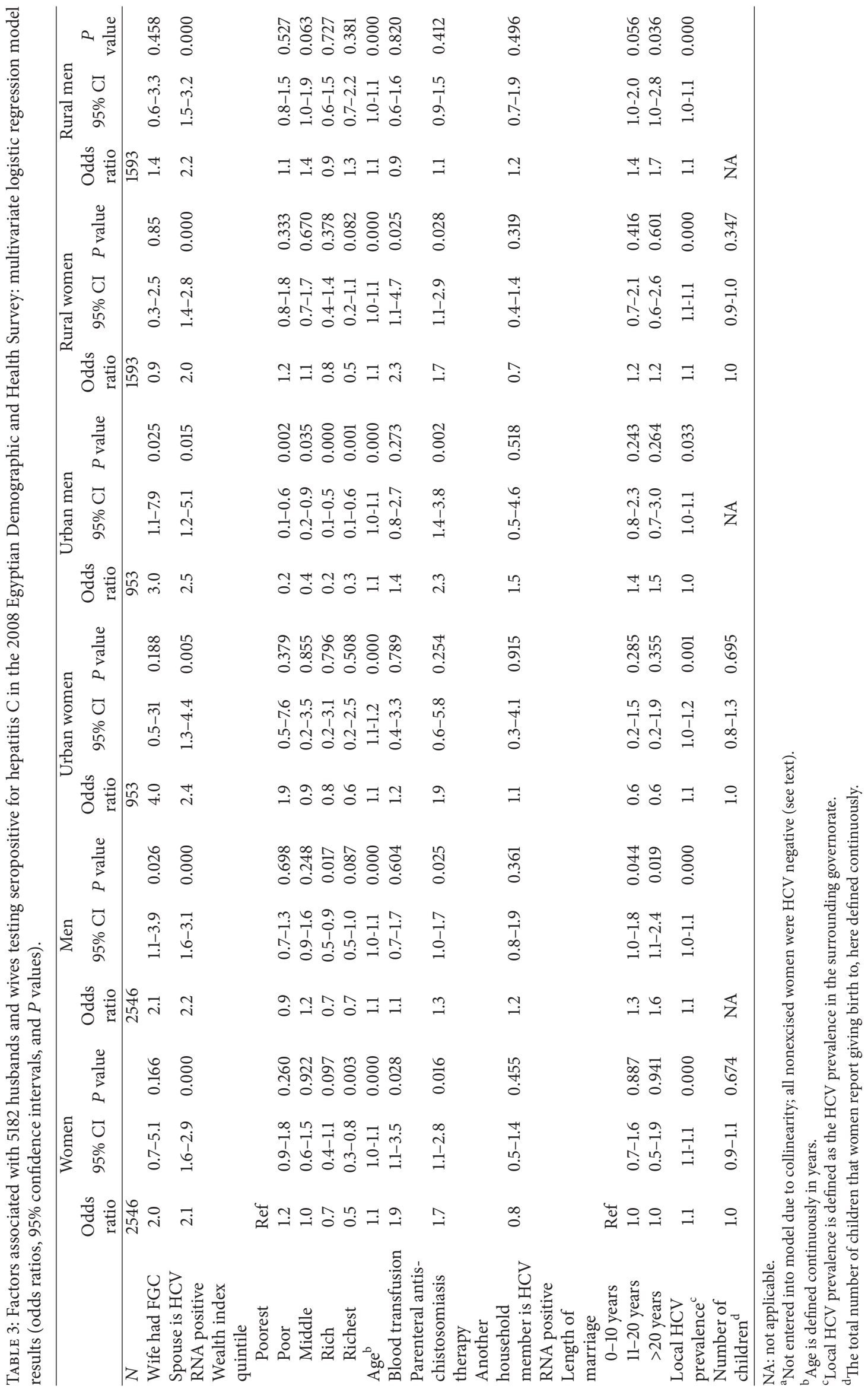


studies from Egypt have found an association between male circumcision performed by informal health care providers and prevalent HCV infection [5, 24].

The anatomical changes produced by FGC, particularly the more extensive forms of FGC, could also promote subsequent female to male and male to female HCV transmission. It is biologically plausible that FGC could both enhance women's susceptibility to the sexual transmission of HCV and increase the chances that $\mathrm{HCV}$ is transmitted to their partner [23]. We cannot however exclude the possibility that the relationship between FGC and $\mathrm{HCV}$ is due to an unmeasured confounding variable.

There is considerable controversy in the literature about the extent to which HCV can be transmitted by sexual contact and cohabitation. In general most studies and two systematic reviews have found that $\mathrm{HCV}$ can be transmitted sexually but that the risk of infection is low $[14,25]$. The most recent systematic review tried to make sense of the conflicting results by dividing the studies into those from high (Japanese) and low (non-Japanese) prevalence regions [14]. They found that pooling the results of studies along these lines provided strong evidence of increased HCV prevalence in offspring of affected persons in endemic areas but no such effect in nonendemic areas. In contrast they found evidence of an increased HCV prevalence amongst the spouses of persons who were HCV seropositive in nonendemic areas but no evidence for this effect in endemic areas. One interpretation of these apparently discordant findings is that HCV prevalence in spouses of $\mathrm{HCV}$ seropositive persons was not higher than controls in endemic areas as the prevalence in the controls was so high [14]. In endemic settings, transmission rates may be so high that close to all susceptible persons are infected by the time they are married. This may mask any effect that domestic and sexual transmission may play. An analogous effect was observed with hepatitis B virus. Sexual transmission was shown to occur in low prevalence areas such as USA but not in high prevalence areas such as East Asia $[26,27]$. More recent studies have found evidence of spousal transmission of HCV in endemic areas [5, 6, 11, 13, 28-30]. Genotypic studies provide further evidence of the spousal transmission of HCV [8, 15, 30, 31].

In Egypt there is an increasing amount of evidence that intrafamilial transmission is an important source of new infections $[5,13,29]$. Two prospective studies investigating the correlates of incident of HCV in Egypt have found evidence of intrafamilial transmission $[13,32]$. One of these was a study that followed up a cohort of $6734 \mathrm{HCV}$ antibody negative persons from 2 rural villages over a median of 1.6 years [13]. In this time there were 33 new HCV infections, 27 of which occurred in families with an anti-HCV positive member. Parenteral factors were not associated with an elevated $\mathrm{HCV}$ incidence and in 21 of the cases there was no history of any parenteral exposure. HCV incidence per 1000 person years was higher in spouses of $\mathrm{HCV}$ antibody positive as opposed to antibody negative persons (13.1 versus 1.9; $P=0.08)$. Men and women with anti-HCV positive spouses were 7 and 2 times as likely to seroconvert as those with seronegative spouses. HCV incidence in children increased in a stepwise manner if they had one of two parents who is $\mathrm{HCV}$ antibody positive. A number of other studies have found marriage to be a risk factor for HCV infection but not all of these are controlled for age, which is likely a significant confounder $[5,6,29]$. One study found that parenteral factors only play a part in explaining prevalent cases in those over the age of 20 in Egypt [6].

One way of tying together the seemingly discordant findings about the extent of intrafamilial HCV transmission from different studies around the world is to apply the insight from hepatitis B virus epidemiology that the predominant mode of transmission may vary considerably between different regions of the world. Hepatitis B transmission in East Asia is predominantly perinatal, in USA it is largely sexual and intravenous drug use $[33,34]$, and in sub-Saharan Africa an important cause is horizontal transmission between children through poorly defined mechanisms [35-37].

In USA, iatrogenic and intravenous drug usage have been shown to be the dominant modes of HCV transmission [17]. There is mounting evidence that sexual transmission is important in HCV outbreaks of men who have sex with men [38]. The best quality evidence however suggests that sexual transmission has not played a large role in HCV transmission among heterosexuals in the USA $[17,39]$.

The composite evidence from Egypt reveals a somewhat different epidemiology for HCV. PAT was clearly important in the initial amplification of $\mathrm{HCV}$ in Egypt [3]. What perpetuated the spread of HCV thereafter? Perinatal transmission can take place. However, most individuals infected by this route clear the virus spontaneously $[6,40]$. Unsterile procedures have clearly played an important role $[1,2,6-$ $8,11]$. A large proportion of cases are however not explained by these factors $[1,6,9,13]$. Our study backs up the evidence from elsewhere of the likelihood of horizontal spread between family/household members $[5,9]$. Some of this may be sexual but much is likely to be via other, as yet unclearly defined, mechanisms [13]. The findings presented here also build on the evidence from elsewhere [1] that FGC may have played a role in the spread of $\mathrm{HCV}$ - both at the time of the procedure and via enhancing the sexual transmission of HCV.

This analysis has a number of serious limitations. The EDHS was a cross-sectional survey and thus the direction of any implied causation cannot be established. Only 5182 individuals (out of 11126 individuals surveyed in the special health topics sample) could be linked together to provide the wife-husband dyad sample used for this analysis. Furthermore the limitations imposed by the linking process meant that the ages of the husbands were from a wider age-band (15-59 years old) than that of the wives (15-49). Because of these limitations, the sample we used cannot be assumed to be representative of whole Egypt.

The uni- and multivariate analyses of the married couple subsample are, however, remarkably similar to those found in analyses of the entire sample of 11126 respondents (presented in Guerra et al. [1]). This suggests that our subsample is not significantly biased.

Given the ongoing high incidence of HCV in Egypt [2], further research is needed to better define the mechanisms for intrafamilial spread so as to guide new prevention strategies. 
In particular further research is needed to ascertain if FGC is an effect-modifier in the sexual transmission of HCV.

\section{Conflict of Interests}

The authors declare that there is no conflict of interests regarding the publication of this paper.

\section{Acknowledgment}

The authors would like to thank Measure DHS (http://www .measuredhs.com) for making these data available.

\section{References}

[1] J. Guerra, M. Garenne, M. K. Mohamed, and A. Fontanet, "HCV burden of infection in Egypt: results from a nationwide survey," Journal of Viral Hepatitis, vol. 19, no. 8, pp. 560-567, 2012.

[2] F. D. Miller and L. J. Abu-Raddad, "Evidence of intense ongoing endemic transmission of hepatitis C virus in Egypt," Proceedings of the National Academy of Sciences of the United States of America, vol. 107, no. 33, pp. 14757-14762, 2010.

[3] C. Frank, M. K. Mohamed, G. T. Strickland et al., "The role of parenteral antischistosomal therapy in the spread of hepatitis C virus in Egypt," The Lancet, vol. 355, no. 9207, pp. 887-891, 2000.

[4] R. Breban, W. Doss, G. Esmat et al., "Towards realistic estimates of HCV incidence in Egypt," Journal of Viral Hepatitis, vol. 20, pp. 294-296, 2013.

[5] M. Habib, M. K. Mohamed, F. Abdel-Aziz et al., "Hepatitis C virus infection in a community in the Nile Delta: risk factors for seropositivity," Hepatology, vol. 33, no. 1, pp. 248-253, 2001.

[6] N. Arafa, M. El Hoseiny, C. Rekacewicz et al., "Changing pattern of hepatitis C virus spread in rural areas of Egypt," Journal of Hepatology, vol. 43, no. 3, pp. 418-424, 2005.

[7] M. Talaat, A. Kandeel, O. Rasslan et al., "Evolution of infection control in Egypt: achievements and challenges," American Journal of Infection Control, vol. 34, no. 4, pp. 193-200, 2006.

[8] A. Paez Jimenez, N. Sharaf Eldin, F. Rimlinger et al., "HCV iatrogenic and intrafamilial transmission in Greater Cairo, Egypt," Gut, vol. 59, no. 11, pp. 1554-1560, 2010.

[9] D. A. Saleh, F. M. Shebl, S. S. El-Kamary et al., "Incidence and risk factors for community-acquired hepatitis $\mathrm{C}$ infection from birth to 5 years of age in rural Egyptian children," Transactions of the Royal Society of Tropical Medicine and Hygiene, vol. 104, no. 5, pp. 357-363, 2010.

[10] D. A. Saleh, F. Shebl, M. Abdel-Hamid et al., "Incidence and risk factors for hepatitis $\mathrm{C}$ infection in a cohort of women in rural Egypt," Transactions of the Royal Society of Tropical Medicine and Hygiene, vol. 102, no. 9, pp. 921-928, 2008.

[11] A. P. Jimenez, M. K. Mohamed, N. S. Eldin et al., "Injection drug use is a risk factor for HCV infection in urban Egypt," PLoS ONE, vol. 4, no. 9, Article ID e7193, 2009.

[12] G. Esmat, M. Hashem, M. El-Raziky et al., "Risk factors for hepatitis $\mathrm{C}$ virus acquisition and predictors of persistence among Egyptian children," Liver International, vol. 32, no. 3, pp. 449456, 2012.

[13] M. K. Mohamed, M. Abdel-Hamid, N. N. Mikhail et al., "Intrafamilial transmission of hepatitis C in Egypt," Hepatology, vol. 42, no. 3, pp. 683-687, 2005.
[14] Z. Ackerman, E. Ackerman, and O. Paltiel, "Intrafamilial transmission of hepatitis C virus: a systematic review," Journal of Viral Hepatitis, vol. 7, no. 2, pp. 93-103, 2000.

[15] N. P. de Cavalheiro, A. de la Rosa, S. Elagin, F. M. Tengan, and A. A. Barone, "Hepatitis $\mathrm{C}$ virus: molecular and epidemiological evidence of male-to-female transmission," Brazilian Journal of Infectious Diseases, vol. 14, no. 5, pp. 427-432, 2010.

[16] E. Z. Fatma and A. Way, Egypt Demographic and Health Survey 2008, Ministry of Health, Cairo, Egypt, 2009.

[17] G. L. Armstrong, A. Wasley, E. P. Simard, G. M. McQuillan, W. L. Kuhnert, and M. J. Alter, "The prevalence of hepatitis C virus infection in the United States, 1999 through 2002," Annals of Internal Medicine, vol. 144, no. 10, pp. 705-714, 2006.

[18] C. Kenyon, J. Buyze, L. Apers, and R. Colebunders, "female genital cutting and hepatitis C spread in Egypt," ISRN Hepatology, vol. 2013, Article ID 617480, 3 pages, 2013.

[19] C. Iavazzo, T. A. Sardi, and I. D. Gkegkes, "Female genital mutilation and infections: a systematic review of the clinical evidence," Archives of Gynecology and Obstetrics, vol. 287, no. 6, pp. 1137-1149, 2013.

[20] L. Morison, C. Scherf, G. Ekpo et al., "The long-term reproductive health consequences of female genital cutting in rural Gambia: a community-based survey," Tropical Medicine and International Health, vol. 6, no. 8, pp. 643-653, 2001.

[21] L. Almroth, S. Elmusharaf, N. El Hadi et al., "Primary infertility after genital mutilation in girlhood in Sudan: a case-control study," The Lancet, vol. 366, no. 9483, pp. 385-391, 2005.

[22] M. C. Inhorn and K. A. Buss, "Infertility, infection, and iatrogenesis in Egypt: the anthropological epidemiology of blocked tubes," Medical anthropology, vol. 15, no. 3, pp. 217-244, 1993.

[23] K. M. Yount and J. S. Carrera, "Female genital cutting and reproductive experience in Minya, Egypt," Medical Anthropology Quarterly, vol. 20, no. 2, pp. 182-211, 2006.

[24] M. K. Mohamed, L. S. Magder, M. Abdel-Hamid et al., "Transmission of hepatitis C virus between parents and children," American Journal of Tropical Medicine and Hygiene, vol. 75, no. 1, pp. 16-20, 2006.

[25] G. Rooney and R. J. C. Gilson, "Sexual transmission of hepatitis C virus infection," Sexually Transmitted Infections, vol. 74, no. 6, pp. 399-404, 1998.

[26] A. S. Lok, C. L. Lai, P. C. Wu, V. C. Wong, E. K. Yeoh, and H. J. Lin, "Hepatitis B virus infection in Chinese families in Hong Kong," American Journal of Epidemiology, vol. 126, pp. 492-499, 1987.

[27] W. Szmuness, M. I. Much, and A. M. Prince, "On the role of sexual behavior in the spread of hepatitis B infection," Annals of Internal Medicine, vol. 83, no. 4, pp. 489-495, 1975.

[28] Y. Akahane, M. Kojima, Y. Sugai et al., "Hepatitis C virus infection in spouses of patients with type C chronic liver disease," Annals of Internal Medicine, vol. 120, no. 9, pp. 748-752, 1994.

[29] L. S. Magder, A. D. Fix, N. N. H. Mikhail et al., "Estimation of the risk of transmission of hepatitis $C$ between spouses in Egypt based on seroprevalence data," International Journal of Epidemiology, vol. 34, no. 1, pp. 160-165, 2005.

[30] J.-H. Kao, P.-J. Chen, P.-M. Yang et al., "Intrafamilial transmission of hepatitis $\mathrm{C}$ virus. The important role of infections between spouses," Journal of Infectious Diseases, vol. 166, no. 4, pp. 900-903, 1992.

[31] C. J. Healey, D. B. Smith, J. L. Walker et al., "Acute hepatitis C infection after sexual exposure," Gut, vol. 36, no. 1, pp. 148-150, 1995. 
[32] A. Mostafa, S. M. Taylor, M. El-Daly et al., "Is the hepatitis C virus epidemic over in Egypt? Incidence and risk factors of new hepatitis C virus infections," Liver International, vol. 30, no. 4, pp. 560-566, 2010.

[33] M. J. Alter, S. C. Hadler, H. S. Margolis et al., "The changing epidemiology of hepatitis B in the United States. Need for alternative vaccination strategies," Journal of the American Medical Association, vol. 263, no. 9, pp. 1218-1222, 1990.

[34] A. Wasley, S. Grytdal, and K. Gallagher, "Surveillance for acute viral hepatitis-United States, 2006," MMWR Surveillance Summaries: Morbidity and Mortality Weekly Report Surveillance Summaries/CDC, vol. 57, no. 2, pp. 1-24, 2008.

[35] F. E. A. Martinson, K. A. Weigle, R. A. Royce, D. J. Weber, C. M. Suchindran, and S. M. Lemon, "Risk factors for horizontal transmission of hepatitis B virus in a rural district in Ghana," American Journal of Epidemiology, vol. 147, no. 5, pp. 478-487, 1998.

[36] H. Whittle, H. Inskip, A. K. Bradley et al., "The pattern of childhood hepatitis B infection in two Gambian villages," Journal of Infectious Diseases, vol. 161, no. 6, pp. 1112-1115, 1990.

[37] S. S. A. Karim, R. Thejpal, and H. M. Coovadia, "Household clustering and intra-household transmission patterns of hepatitis B virus infection in South Africa," International Journal of Epidemiology, vol. 20, no. 2, pp. 495-503, 1991.

[38] A. T. Urbanus, T. J. Van De Laar, I. G. Stolte et al., "Hepatitis C virus infections among HIV-infected men who have sex with men: an expanding epidemic," AIDS, vol. 23, no. 12, pp. F1-F7, 2009.

[39] C. Vandelli, F. Renzo, L. Romanò et al., "Lack of evidence of sexual transmission of hepatitis $\mathrm{C}$ among monogamous couples: results of a 10-year prospective follow-up study," American Journal of Gastroenterology, vol. 99, no. 5, pp. 855-859, 2004.

[40] F. M. Shebl, S. S. El-Kamary, D. A. Saleh et al., "Prospective cohort study of mother-to-infant infection and clearance of hepatitis C in rural Egyptian villages," Journal of Medical Virology, vol. 81, no. 6, pp. 1024-1031, 2009. 


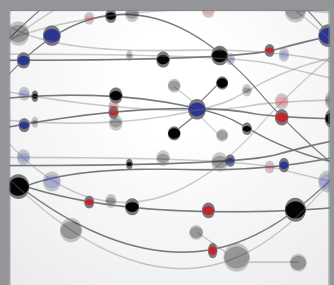

The Scientific World Journal
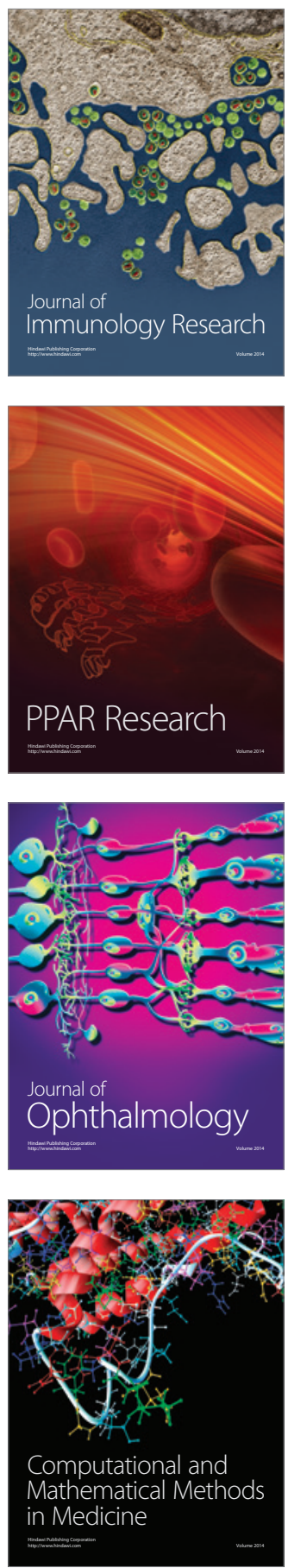

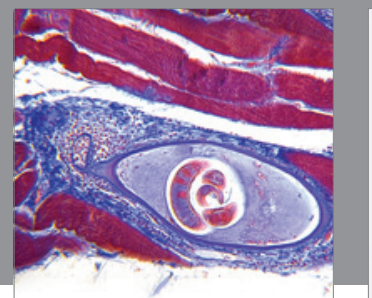

Gastroenterology

Research and Practice
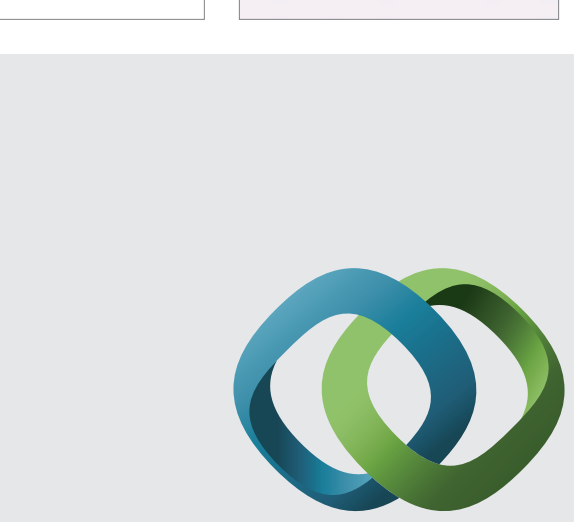

\section{Hindawi}

Submit your manuscripts at

http://www.hindawi.com
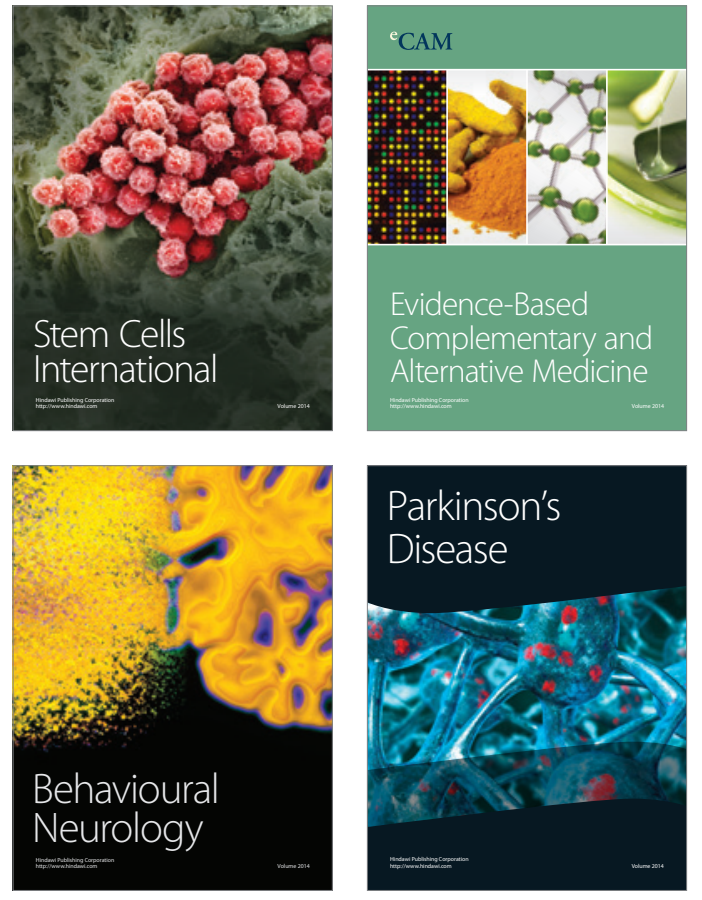
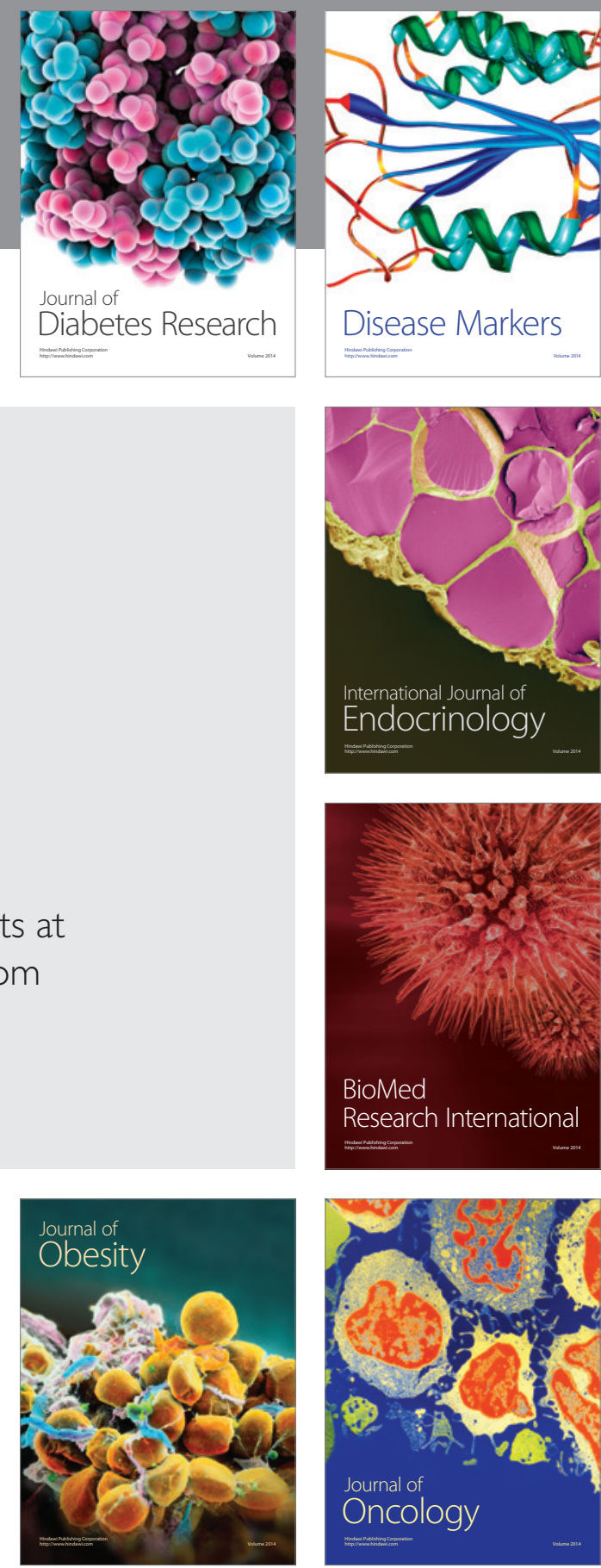

Disease Markers
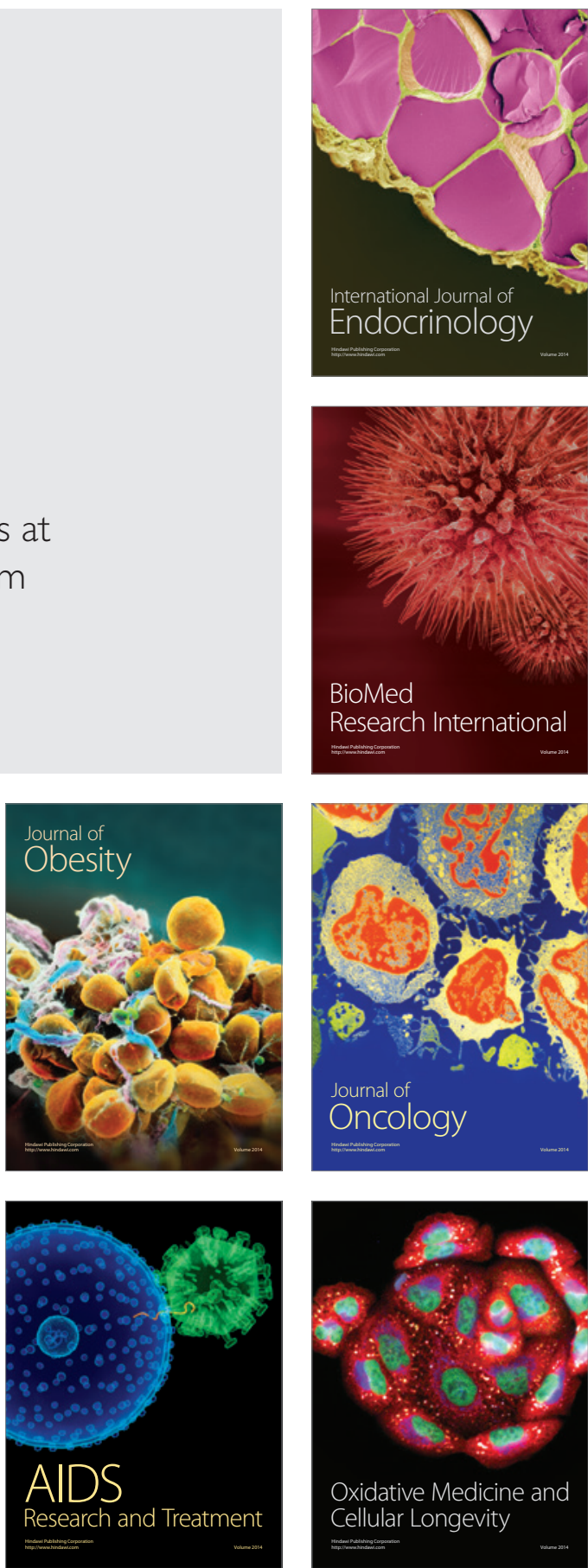